\title{
CARBON NANOTUBES-IONIC LIQUID GEL. CHARACTERIZATION AND APPLICATION TO PSEUDOEPHEDRINE AND CHLORPHENIRAMINE DETERMINATION IN PHARMACEUTICALS
}

\author{
M. PÉREZ-ORTIZ, P. PIZARRO, A. ÁLVAREZ-LUEJE* \\ Chemical and Pharmaceutical Sciences Faculty, University of Chile, PO Box 233, Santiago, Chile.
}

\begin{abstract}
A multi-walled carbon nanotube (MWCNT)-ionic liquid (IL) film-modified glassy carbon electrode (GCE) was constructed for the determination of pseudoephedrine (PE) and chlorpheniramine (CP) by differential pulse voltammetry (DPV).

The MWCNT-IL film has shown an obvious electrocatalytic activity towards oxidation of PE and CP, since it increases the electroactive area, facilitates the electron transfer and significantly enhances the oxidation peak current of both. Also a synergistic effect between MWCNT and IL was detected; it improves the conductivity, resulting in a better response, thus the modified electrode presented higher sensitivity.

Under the optimum conditions, the oxidation peak currents were linearly proportional to the concentration in the range from 40.3 to $161.3 \mu \mathrm{g} / \mathrm{mL}$ for $\mathrm{PE}$ and from $0.39 \mu \mathrm{g} / \mathrm{mL}$ to $27.4 \mu \mathrm{g} / \mathrm{mL}$ for CP. Detection limits were $32.4 \mu \mathrm{g} / \mathrm{mL}$ with $180 \mathrm{~s}$ accumulation for PE and $0.11 \mu \mathrm{g} / \mathrm{mL}$ with $240 \mathrm{~s}$ accumulation for CP.

Finally, the proposed sensitive and simple electrochemical method was successfully applied to PE and CP determination in a pharmaceutical formulation, and recoveries were acceptable.
\end{abstract}

Keywords: Pseudoephedrine, Chlorpheniramine, Carbon nanotubes, Ionic liquids, Modified electrodes, Voltammetry

\section{INTRODUCTION}

Pseudoephedrine (PE) and chlorpheniramine (CP) are drugs that usually combined in one formulation for symptomatic treatment of coughs and the common cold. PE is a sympathomimetic agent and produces constriction of blood vessels, eradicating mucous membrane congesting and tumefying of nasopharynx, relieving symptom of the nasal congestion ${ }^{1}$. CP is a potent antihistaminic that causes a moderate degree of sedation and is used for the allergic disease $\mathrm{e}^{2}$.

Various analytical methods have been reported in literature for the simultaneous determination of $\mathrm{PE}$ and $\mathrm{CP}$ in pharmaceutical preparations. These include capillary electrophoresis ${ }^{3,4}$, liquid chromatography-tandem mass spectrometry ${ }^{5-7}$, reversed-phase high-performance liquid-chromatography (HPLC) $^{8-12}$ and micellar liquid chromatography ${ }^{13}$. Most of the reported methods require sample pretreatment and extraction of the drug prior to the analysis. These methods are time consuming, intensive solvent-usage and require expensive devices and maintenance.

In the best of our knowledge, no electrochemical method to determine simultaneously these drugs has been reported. CP has been determined in pharmaceuticals using polarography ${ }^{14}$ and by differential pulse voltammetry (DPV) using carbon paste electrodes ${ }^{15-16}$, carbon paste electrodes modified with cobalt nanostructures ${ }^{17}$ and modified glassy carbon electrodes ${ }^{18}$. Also, the electrochemical oxidation of $\mathrm{CP}$ at polytyramine film doped with ruthenium (II) complex, devoted with kinetic and thermodynamic studies have been described $^{19}$. On the other hand, the anodic oxidation at a glassy carbon electrode $^{20}$, the electrocatalytic oxidation at multi-wall carbon nanotube modified glassy carbon electrode ${ }^{21}$ and the adsorptive stripping voltammetric determination at carboxylated multi-walled carbon nanotube-modified electrode ${ }^{22}$ have been described for PE.

Drugs analysis is one of the important tools for drug quality control. Therefore, the development of simple, sensitive, rapid and reliable method for the dete mination of these drugs is of great importance. Electrochemical detection of analyte is a very elegant method in analytical chemistry and electrochemical sensors satisfy many of the requirements for such tasks particularly owing to their inherent specificity, rapid response, sensitivity and simplicity of preparation for the determination of organic molecules, including drugs and related molecules in pharmaceutical dosage forms and biological fluids.

According to the above, in the present work we produced and characterized a multi-walled carbon nanotube-ionic liquid (1-butyl-3-methylimidazolium hexafluorophosphate) film-modified glassy carbon electrode to be applied to the study of the electrochemical behaviour of PE and $\mathrm{CP}$, and to develop different pulse voltammetric method to determine these drugs in a dosage form.

\section{EXPERIMENTAL}

Apparatus

Cyclic voltammetric (CV) and differential pulse voltammetry (DPV) experiments were performed using a multichannel $\mathrm{CHI}$ 1030B potentiostat (Shanghai Chenhua Co., China) controlled by a computer with 1030B CH software. A conventional three-electrode system was adopted. A glassy carbon electrode $(\varnothing=3.5 \mathrm{~mm})$ or a modified glassy carbon electrode was used as the working electrode, a platinum wire as the counter electrode (auxiliary), and an $\mathrm{Ag} / \mathrm{AgCl}$ electrode as the reference. All the electrochemical measurements were conducted at room temperature (about $25^{\circ} \mathrm{C}$ ) by triplicate.

Morphological characterization of the electrodes was carried out by Scanning Electrochemical Microscopy (SECM) using a CHI900 Scanning electrochemical microscope, $\mathrm{CH}$ Instruments, scanning area $100 \mu \mathrm{m} \times 100 \mu \mathrm{m}$, and by Scanning electron microscopy (SEM) using a Jeol JSM-5410 SEM (Tokyo, Japan), electron acceleration voltage (EHT): $10.00 \mathrm{kV}$, working distance (WD): $7.5 \mathrm{~mm}$, spotsize: 220, Magnification: 500x -10.0x.

HPLC measurements were carried out by using a Jasco assembly equipped with a controller pump (PU-2089S), a column oven (CO-2060) and a photodiode array detector (MD-2018). The data acquisition was performed by ChromNav software. Chromatography was performed on Kinetex-Phenomenex reversed-phase (Torrance, CA, USA) C-18 column at $40{ }^{\circ} \mathrm{C}$, a $20 \mu \mathrm{L}$ injection loop (Rheodyne valve) and a UV detector set at $210 \mathrm{~nm}$.

\section{Chemicals and Solutions}

Multi-walled carbon nanotubes (MWCNT) and multi-walled carbon nanotubes functionalized with carboxylic acid (MWCNT-COOH) (diameter: $10 \mathrm{~nm}$, length: $1.5 \mu \mathrm{m}$, purity: $95 \%$ ), single-walled carbon nanotubes (SWCNT) (diameter: $2 \mathrm{~nm}$, length 5-30 um, purity: $80 \%$ ) and single-walled carbon nanotubes functionalized with carboxylic acid (SWCNT-COOH) (diameter: 2 $\mathrm{nm}$, length 5-30 $\mu \mathrm{m}$, purity: $95 \%$ ) were obtained from Dropsens nanomaterials (Spain). 1-butyl-3-methylimidazolium hexafluorophosphate (BMIMPF6, purity $\geq 98.5 \%$ ), 1-butyl-3-methylimidazolium tetrafluoroborate (BMIMBF4, purity $\geq 98.5 \%$ ), 1-butil-4-methylpyridinium hexafluorophosphate (BMPIRPF6, purity $\geq 97 \%$ ), 1-butyl-4-methylpyridinium tetrafluoroborate (BMPIRBF4, purity $\geq 97 \%$ ), pseudoephedrine hydrochloride (purity $\geq 98 \%$ ) and chlorpheniramine maleate (purity $\geq 99 \%$ ) were purchased from Sigma-Aldrich.

Hexaammineruthenium (III) chloride and ferrocenemethanol came from Sigma-Aldrich, and potassium ferricyanide from Merck. Acetonitrile HPLC grade was obtained from Merck. All other reagents used were of pro-analysis quality and all solutions were prepared with water obtained from a Milli-Q Ultra-Pure Water System.

A $0.1 \mathrm{M}$ Britton-Robinson buffer (an acetic, boric and phosphoric acid mixture) was used. The required $\mathrm{pH}$ was obtained through the addition of concentrated $\mathrm{NaOH}$ or $\mathrm{HCl}$ solutions.

Standard stock solutions of $\mathrm{PE}$ or $\mathrm{CP}$ were prepared daily in Milli-Q water at a constant concentration of $1 \times 10^{-2} \mathrm{M}$ and $1 \times 10^{-3} \mathrm{M}$, respectively, and stored protected from light using amber glass containers. For working solutions, appropriate volumes of the stock solutions were diluted to $5 \mathrm{~mL}$ with $0.1 \mathrm{M}$ Britton-Robinson buffer to obtain concentration of $1 \mathrm{mM}$. 
Preparation of the Modified Glassy Carbon Electrodes

Previous to modification, the glassy carbon electrode (GCE) was mechanically polished with alumina $(0.3$ and $0.05 \mu \mathrm{m})$ and thoroughly washed with Milli-Q water. To modify the GCE, $1 \mathrm{mg}$ carbon nanotubes (CNT) was dispersed in $1 \mathrm{~mL}$ dimethylformamide (DMF) and sonicated for $15 \mathrm{~min}$; then 10 $\mu \mathrm{L}$ of this dispersion were deposited onto the GCE and dried in an oven at 50 ${ }^{\circ} \mathrm{C}$ for $15 \mathrm{~min}$ (GCE-CNT). In addition, appropriate amounts of CNT and IL (to obtain ratios of 1:10, 1:20 or 1:30 w/w, respectively) were mixed and homogenized in a mortar for 20 min until a black gel was obtained. The gel was then mechanically adhered to the surface of the GCE with a spatula. The thickness and area of the gel film were controlled using a membrane thickness of $10 \mu \mathrm{m}$ with a hole of $3.5 \mathrm{~mm}$ diameter (GCE-CNT-IL).

\section{Characterization of the modified electrodes}

Determination of the electroactive area

The electrochemically effective surface areas were calculated $u$ ing a chronocoulometric method with a $0.1 \mathrm{mM} \mathrm{K}_{3}\left[\mathrm{Fe}(\mathrm{CN})_{6}\right]$ solution containing $1 \mathrm{mM}$ $\mathrm{KCl}$, according to the Anson equation ${ }^{23}$ :

$$
Q(t)=2 n F C D^{1 / 2} t^{1 / 2} \pi^{-1 / 2}+Q_{\mathrm{dl}}+Q_{\mathrm{ads}}
$$

in which $\mathrm{A}$ is the surface area of the working electrode, $\mathrm{C}$ is the concentration of the substrate, $\mathrm{D}$ is the diffusion coefficient $\left(7.6 \times 10^{-6} \mathrm{~cm}^{2} \mathrm{~s}^{-1}\right)^{24}, \mathrm{Q}_{\mathrm{dl}}$ is the double-layer charge which could be eliminated via background subtraction, and $\mathrm{Q}_{\mathrm{ads}}$ is the Faradaic charge.

\section{Analytical Procedure}

Calibration Curves

Working solutions ranging from $0.4 \mu \mathrm{g} / \mathrm{mL}$ to $27.4 \mu \mathrm{g} / \mathrm{mL}$ for $\mathrm{CP}$ and 40.3 $\mu \mathrm{g} / \mathrm{mL}$ to $161.4 \mu \mathrm{g} / \mathrm{mL}$ for PE were prepared by diluting drug stock solutions with $0.1 \mathrm{M}$ Britton-Robinson buffer.

Limit of detection (LOD) and limit of quantification (LOQ) were calculated according to the following equations:

$$
L O D=\frac{Y_{b l}+3 \sigma_{b l}}{m} \quad L O Q=\frac{Y_{b l}+10 \sigma_{b l}}{m}
$$

Where:

$\mathrm{m}=$ Calibration curve slope

$Y_{b l}=$ Blank response

$\sigma_{b l}=$ Blank standard deviation

Sample preparation

Rinoven ${ }^{\circledR}$ tablets (containing $60 \mathrm{mg} \mathrm{PE}$ and $4 \mathrm{mg} \mathrm{CP}$ ) were powdered in a mortar, and a solution equivalent to $1.0 \times 10^{-4} \mathrm{M}$ PE was prepared. The $\mathrm{pH}$ of the solution was adjusted to 10 for $\mathrm{CP}$ quantification and then it was changed to $\mathrm{pH} 12$ for the quantification of PE. Two different solutions were analyzed by triplicate by standard addition method.

\section{RESULTS AND DISCUSSION}

Different types of CNT were assayed, and MWCNTs were chosen since these showed more well-defined redox couple and the highest anodic and cationic currents (Fig. 1).

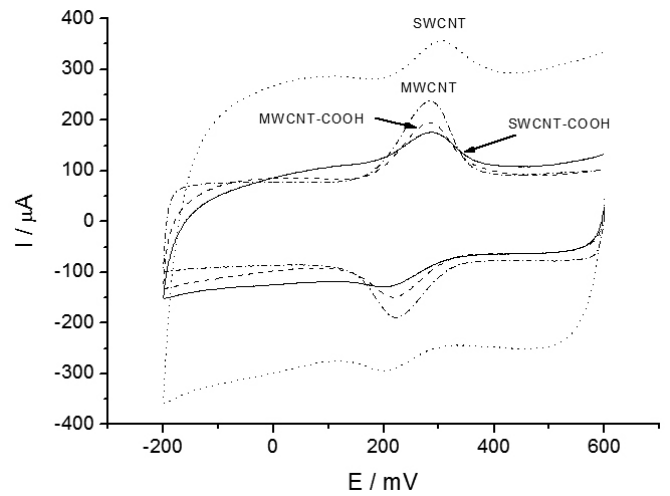

Figure 1. CNTs effect on CVs for $1 \mathrm{mM}$ ferrocenemethanol, using GCECNT at 1:20 ratio.
In order to determine the IL that shows the best signals of the redox couple, the four ILs under study (BMIMPF6, BMIMBF4, BMPIRPF6, BMPIRBF4) were tested with three redox mediators: ferrocenemethanol, potassium ferrocyanide and hexamin ruthenium (Fig. 2). In this regard all modified electrodes showed better redox couples (higher peak current values) than GCE without modification, but examine ruthenium showed the lowest current peaks (Ip). On the other hand, a best response was obtained with negatively charged redox mediators (ferrocenemethanol $>$ ferrocyanide). Ferrocenemethanol showed the highest current peaks (Ip) with all ILs assayed, being more intense when BMIMPF6 was used.

This result revealed that the charge of the analyte plays an important role in the type of interaction between it and the CNT-IL gel, so the interactions are favored when the analyte is negatively charged.

Additionally, BMIMPF6 showed to favor the reversibility for ferricyanide $(\triangle \mathrm{Epa}-\mathrm{Epc}=0.59 \mathrm{~V})$. This was not observed for any other ionic liquid studied.

The IL was selected mainly considering the stability of the electrode. By using moderately water-soluble ILs (such as BMIMBF4) the electrode was less stable and therefore less possibilities of analyte accumulation, thus ILs insoluble in water were considered. Of these, BMPIRPF6 is in solid state, which hampering the gel formation and handling, hence BMIMPF6 was selected. BMIMPF6 showed the highest current intensity with all redox mediators assayed when it was compared with the others ILs, and also proved to favor the reversibility of the process for ferrocenemethanol.

Once the type of IL was selected, we optimized the mass ratio of MWCNTs and IL in MWCNTs-IL-Gel, so different ratios of MWCNTs:IL were tested $(1: 10,1: 20,1: 30 \mathrm{w} / \mathrm{w})$. From Fig. 3, one can see that the current response is the highest when the mixing ratio of CNTs to IL is $1: 10$. If there is too much IL in the gel, the current response will decrease. This fact may be attributed to the solvent effect of IL, since CNTs are wrapped up by the IL. The advantage/ the potential of CNTs was counteracted if the ratio of IL in the gel was too high. However at high ratios a decrease in the capacitive load current was observed. Therefore, an intermediate ratio of 1:20 was selected.

Characterization of MWCNTS-IL-Gel/GCE

The electroactive surface area for the electrodes (MWCNTs/GCE, MWCNTs-IL-gel/GCE and GCE) was calculated using chronocoulometry according to the Anson equation. Based on the slope of the linear relationship between charge (Q) and time (t), the area values (A) for the bare GCE, GCE-CNT and GCE-CNT-IL were calculated to be $0.01 \mathrm{~mm}^{2}, 0.02 \mathrm{~mm}^{2}$ and $0.25 \mathrm{~mm}^{2}$, respectively. These results indicate that the electrode's effective surface area increased 25 fold after electrode modification with the IL, improving the current response and decreasing the detection limit.

The surface morphology of the constructed electrodes was investigated using scanning electron microscopy (SEM) and Electrochemical Scanning Microscopy (SECM) (Figs. 4 and 5).

Fig. 4A shows the typical SEM image of the MWCNTs dispersed in DMF by sonication. It can be seen that MWCNTs were highly agglomerated, while MWCNTs-IL-Gel sample was more homogeneous (Fig. 4B). MWCNTs seemed to have been wrapped by the IL, facilitating their dispersion to cover the surface of the electrode, which is consistent with previous reports ${ }^{24,25}$. The film deposited at the surface of the GCE formed a three-dimensional structure and reticular formation revealing a much larger surface area than electrode geometric area, which is consistent with capacity studies.

SECM images reveal a large difference in conductivity among the measured electrodes. For GCE (Fig. 5A) a homogeneous surface and a conductivity expected by the reports in the literature were observed ${ }^{27}$. In the second case (MWCNTs/GCE, Fig. 5B), the surface was no longer so homogeneous, what was expected for a modified electrode, but a slight increase in conductivity was observed. Finally, a less homogeneous surface associated with a considerable increase in conductivity was observed in MWCNTs-IL-gel/GCE (Fig. 5C). 

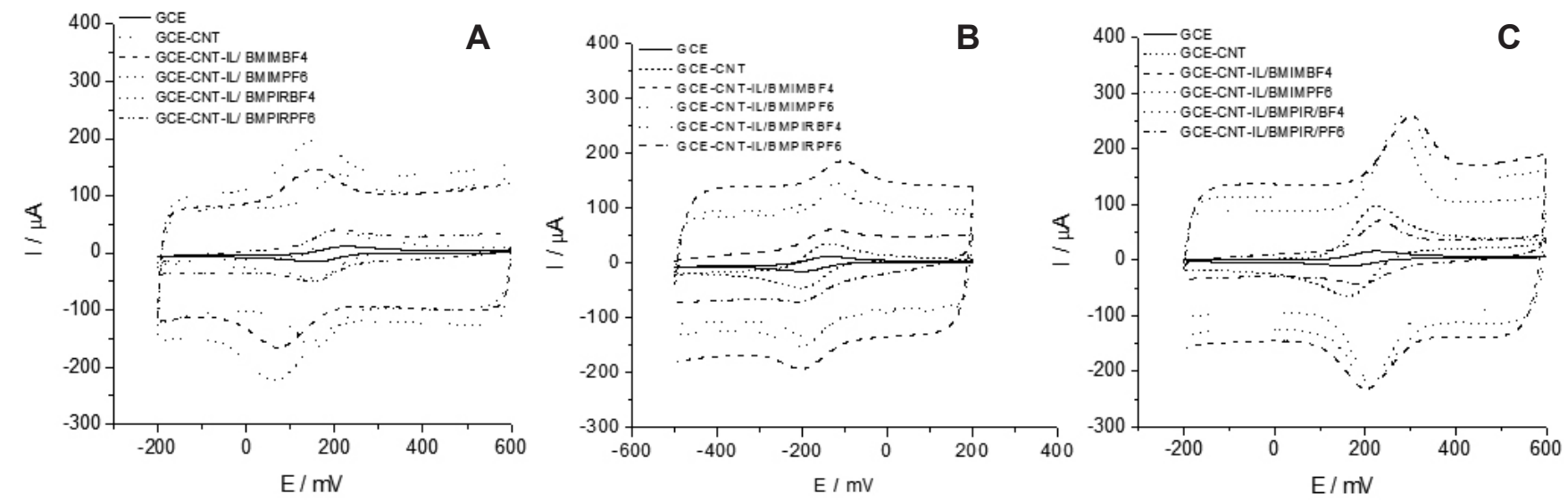

Figure 2. CVs using GCE-CNT-IL for: (A) $1 \mathrm{mM}$ potassium ferricyanide, (B) $1 \mathrm{mM}$ ferrocenemethanol and (C) $1 \mathrm{mM}$ hexamine ruthenium chloride.

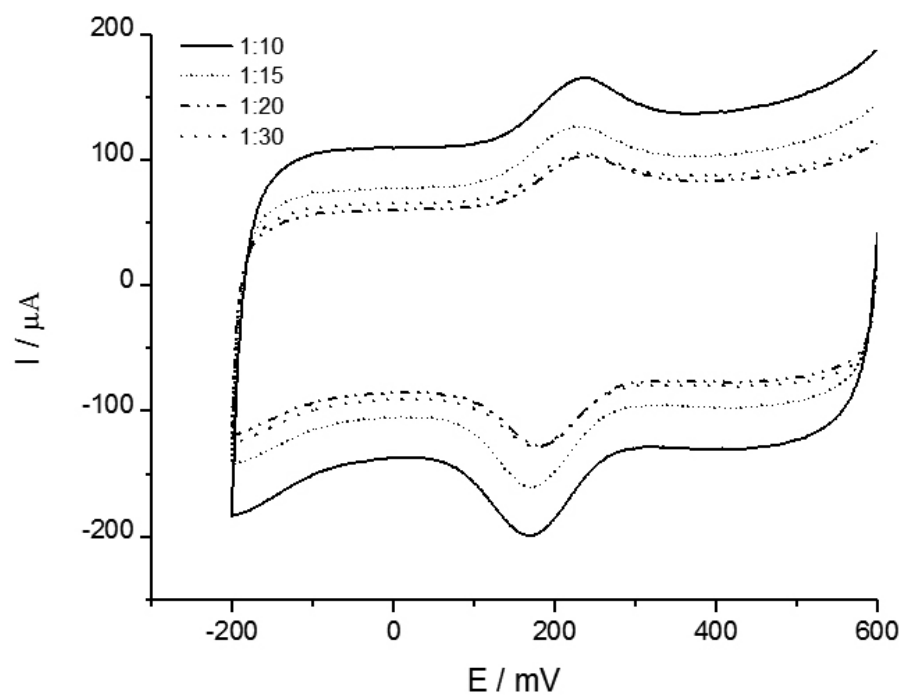

Figure 3. CVs of GCE-CNT-IL for $1 \mathrm{mM}$ potassium ferricyanide at different mass ratios of CNT: IL. (100 mV/s).

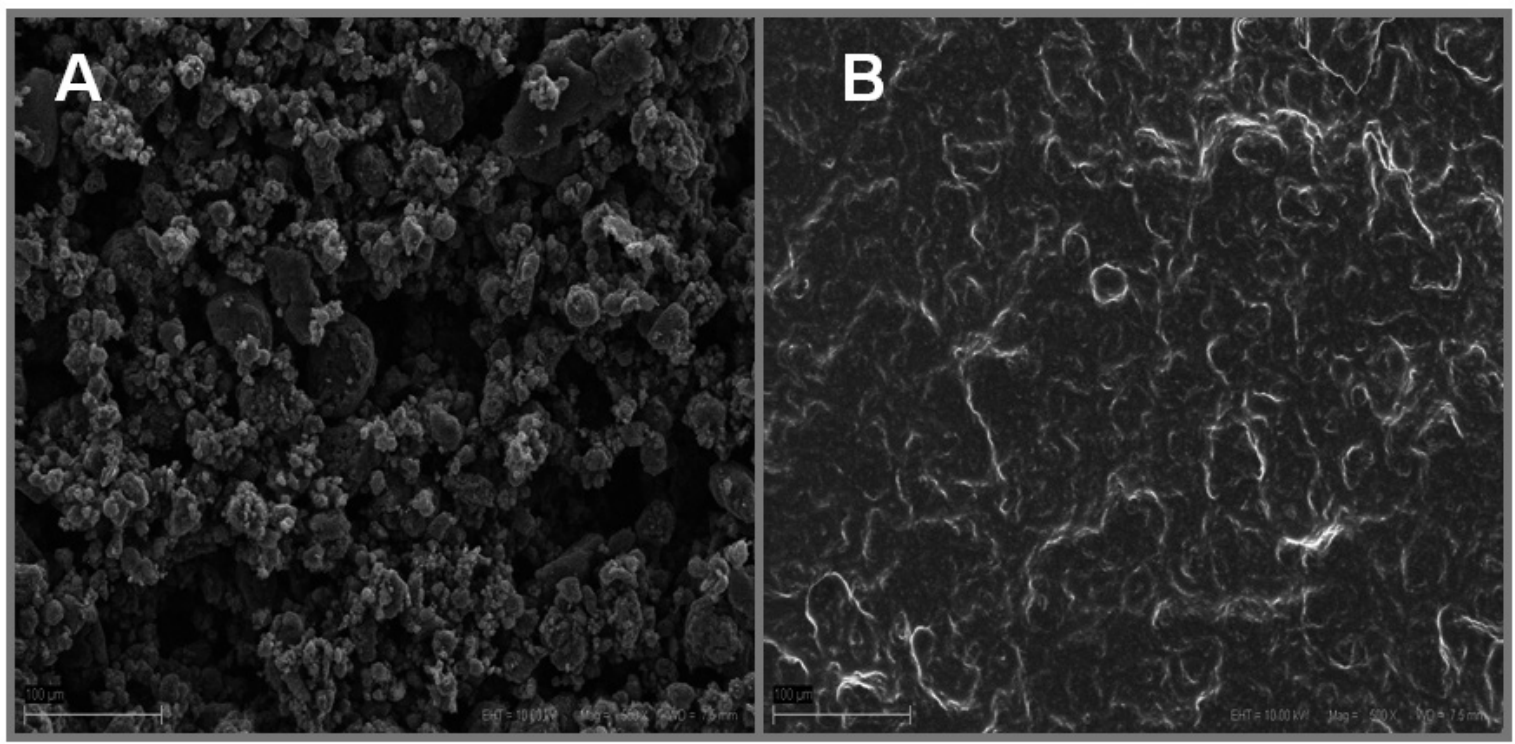

Figure 4. SEM images (acceleration of $10 \mathrm{kV}$, scale $100 \mu \mathrm{m}$ ) of (A) MWCNTs dispersed in DMF by sonication and (B) MWCNTsIL-Gel (1:20). 

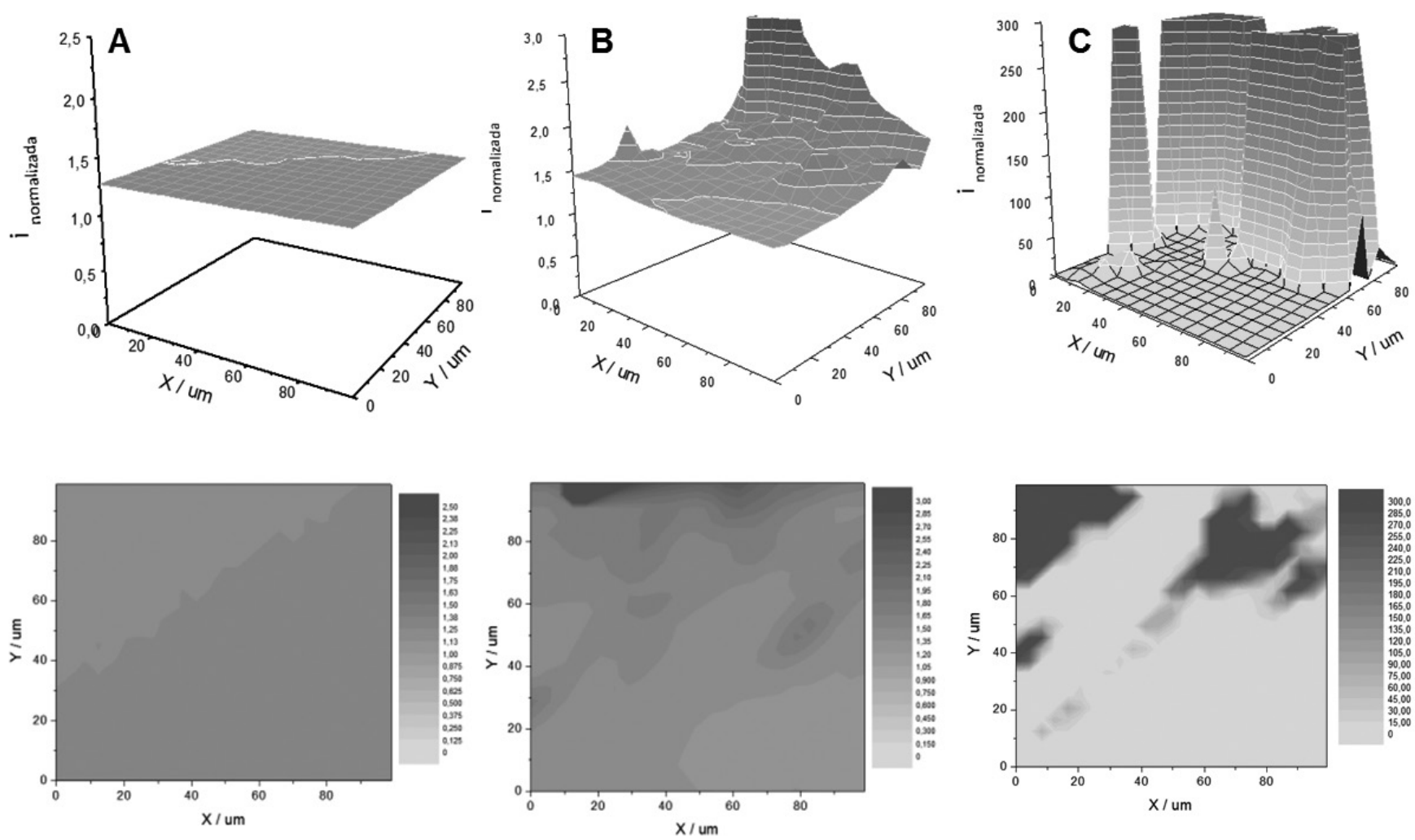

Figure 5. SECM images, ferrocenemethanol in buffer Britton-Robinson 0.1 M pH 7.4 (top: 3D images, bottom: 2D images) for: (A) GCE, (B) MWCNTs/ GCE and (C) MWCNTs-IL-gel/GCE.

The above results demonstrate that there were more electroactive sites exposed in the film formed by MWCNTs and IL, this may be due to the interactions between MWCNTs and IL by Van der Waals forces, which disentangle the CNT agglomerations, and in addition MWNTs-IL-Gel has shown larger electroactive surface area. Hence, from these results can be concluded that the synergistic effect between CNT and IL improves the conductivity, and would allow obtaining a better response increasing sensitivity.

The modified electrodes were also characterized using cyclic voltammetry (CV) to quickly determine the behaviour of the three redox mediators assayed: ferrocenemethanol, potassium ferricyanide and hexamine ruthenium chloride. Fig. 6 present the $\mathrm{CVs}$ of $\left[\mathrm{Fe}(\mathrm{CN})_{6}\right]^{3-} /\left[\mathrm{Fe}(\mathrm{CN})_{6}\right]^{4-}$, ferrocene/ferricinium and $\left[\mathrm{Ru}(\mathrm{NH} 3)_{6}\right]^{3+} /\left[\mathrm{Ru}\left(\mathrm{NH}_{3}\right)_{6}\right]^{2+}$ redox couples obtained with GCE, MWCNTs/GCE and MWCNTs-IL-gel/GCE. The voltammograms exhibited well-defined peaks and an increase in both the anodic and cathodic currents as the electrode was modified for the three mediators. The greatest difference was obtained with MWCNTs-IL-gel/GCE, which exhibited improved electrocatalytic activity over that of the unmodified electrode and MWCNTs modified electrode, thus confirming the effect of the IL.

In the case of ferricyanide, an improvement in the reversibility of the redox process was observed (data not shown). The difference between anodic and cathodic peak potentials $(\Delta \mathrm{Ep}-\mathrm{Ep})$ decreases near $60 \mathrm{mV}$ as the electrode was modified. However, for the others redox mediators, the $\Delta \mathrm{Ep}_{\mathrm{c}}$ increased as the electrode was modified with MWCNTs, but returned to values close to the initial (bare electrode) when IL was adding. The peak-to-peak separation could be interpreted as average resistance possible due to carbon-carbon contacts.

The background currents of the GCE, MWCNTs/GCE and MWCNTs-ILgel/GCE were also compared (data not shown). A high background response was obtained on the MWCNTs-IL-gel/GCE due to the high capacitance of the IL. The results were in accordance with previous reports regarding the IL-modified electrodes ${ }^{28}$

Electrochemical characterization of drugs on MWCNTs-IL-gel/GCE

The redox behavior of $\mathrm{CP}$ and PE was studied at both bare and modified GCE by CV. Poorly defined anodic current responses were observed during the scanning from 0 to $1000 \mathrm{mV}$ in both cases on GCE (Fig. 7, insets). On the reverse potential scans, there was no corresponding reduction peak, suggesting that the electrode reactions of $\mathrm{CP}$ and $\mathrm{PE}$ are totally irreversible. Additionally, it is important to mention that both drugs showed a better response on MWCNTsIL-gel/GCE, with current intensities 100 and 45 fold higher than on bare GCE. Therefore, it can be affirmed that by modifying the electrode is possible to increase the sensitivity towards these drugs.

The effect of $\mathrm{pH}$ on the electrochemical response of these drugs was studied over the $\mathrm{pH}$ range of 2-12 in Britton Robinson buffer.

$\mathrm{CP}$ displayed a well-defined anodic signal on the MWCNTs-IL-gel/GCE over a broad $\mathrm{pH}$ range $(\mathrm{pH} 2-12)^{16,17}$. This signal appears $\mathrm{pH}-$ dependent and is shifted toward lower anodic potentials as the $\mathrm{pH}$ increases, facilitating the oxidation process. The E-pH plot showed two linear zones with slopes of -51.8 and $-12 \mathrm{mV} / \mathrm{pH}$ and a break at $\mathrm{pH} 10$. This break is due to changes in the protonation-deprotonation equilibrium related to one $\mathrm{pK}$ of $\mathrm{CP}$ reported near of $9^{29}$. In contrast, peak current increases as the $\mathrm{pH}$ increases with a maximum at $\mathrm{pH}$ 12, which was the $\mathrm{pH}$ selected for further analytical studies (Fig. 8).

In the same way as for $\mathrm{CP}$, the electrochemical response of PE was studied over a wide range of $\mathrm{pH}$ (Fig. 9). However, the peak of the oxidation process just appeared in the $\mathrm{pH}$ interval $9-12^{30,31}$. In this $\mathrm{pH}$ range it was possible to observe that as the $\mathrm{pH}$ value was increased (above 10), the oxidation peak shifted to less positive potentials with an increase in peak currents, being this maximum at $\mathrm{pH}$ 12. The peak potential (Ep) also showed a linear relationship, and the regression equation was: $\mathrm{Ep}(\mathrm{mV})=-49.1 \mathrm{pH}+1030(\mathrm{r}=0.995)$.

Finally, the effect of scan rate on the oxidative peak currents was also evaluated. For PE variation of the scan rate in the range of 10-500 $\mathrm{mV} / \mathrm{s}$ resulted in a linear relationship between the anodic peak current and the square-root of a scan rate (data not shown). This indicates that the electrode process was controlled by diffusion rather than adsorption. Additionally, a plot of logarithm of peak current versus logarithm of scan rate gave a straight line: $\log$ Ip $=0.59$ $\log v+1.45\left(r^{2}=0.979\right)$, with a slope very close to the theoretical value of 0.5 , an expected value for an ideal reaction of solution species. On the other hand, the same graph for CP showed a linear relationship with a slope between 0.5 and $1\left(\log \mathrm{Ip}=0.71 \log \mathrm{v}+1.45, \mathrm{r}^{2}=0.998\right)$, indicating that the redox process involved in the oxidation of the compound is a mixed process, which is controlled by diffusion and adsorption of the electroactive species on the working electrode ${ }^{32}$. 

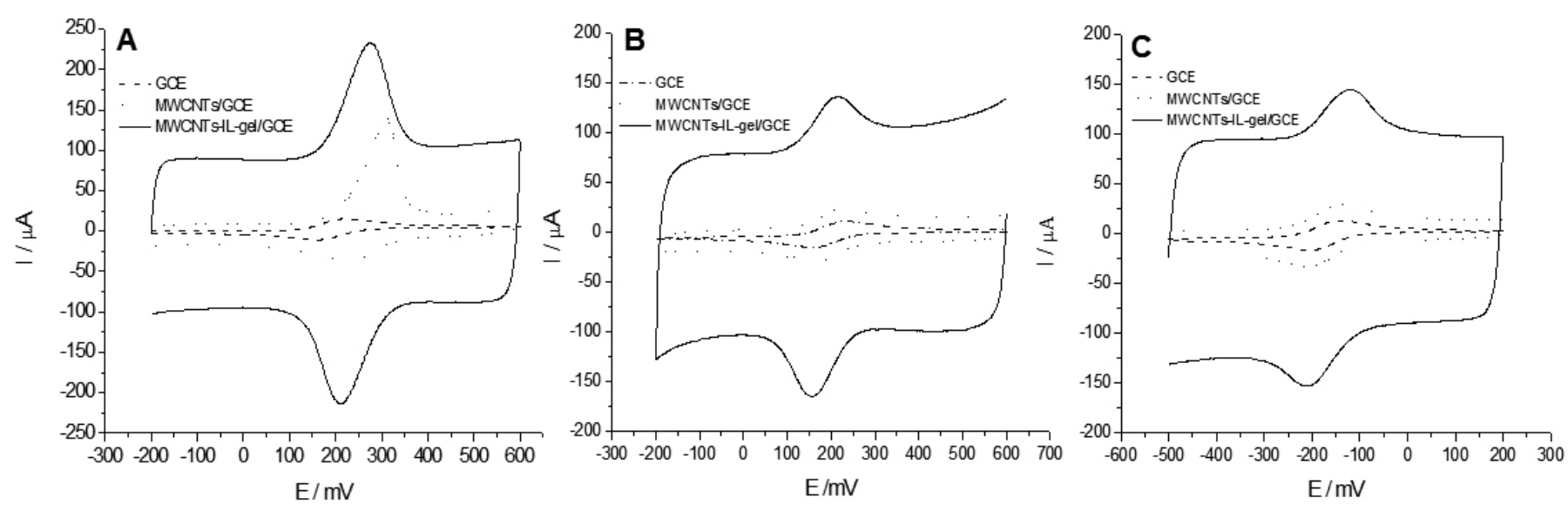

Figure 6. Comparative CVs for (A) ferrocenemethanol, (B) potassium ferrocyanide and (C) hexamine ruthenium chloride using three different electrodes.
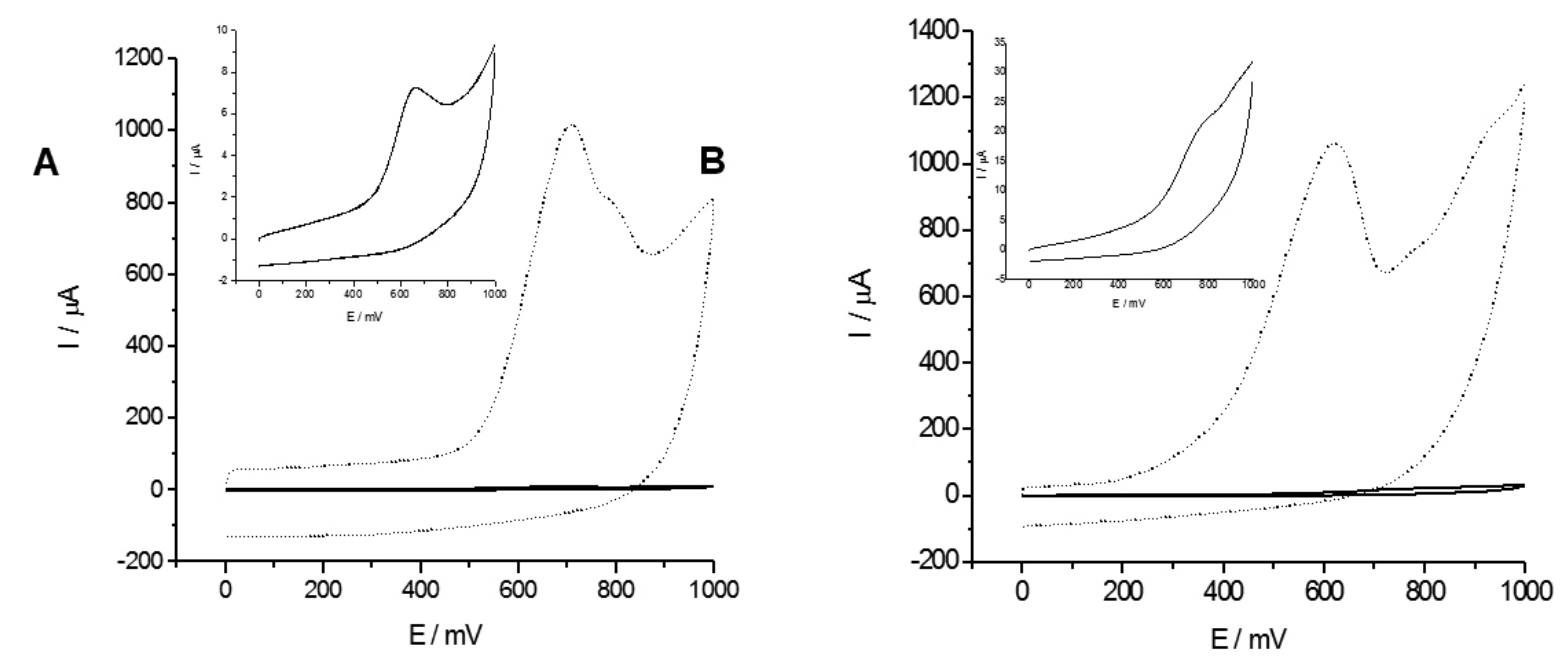

Figure 7. CVs of: (A) CP $(0.1 \mathrm{mM}$ ) at a bare GCE (solid line) and the MWCNTs-IL-gel/GCE (solid line) in $0.1 \mathrm{M}$ Britton Robinson buffer $\mathrm{pH}$ 10. (B) PE (1 mM) at a bare GCE (solid line) and the MWCNTs-IL-gel/GCE (solid line) in $0.1 \mathrm{M}$ Britton Robinson buffer pH 12. Insets: amplified responses at a bare GCE.
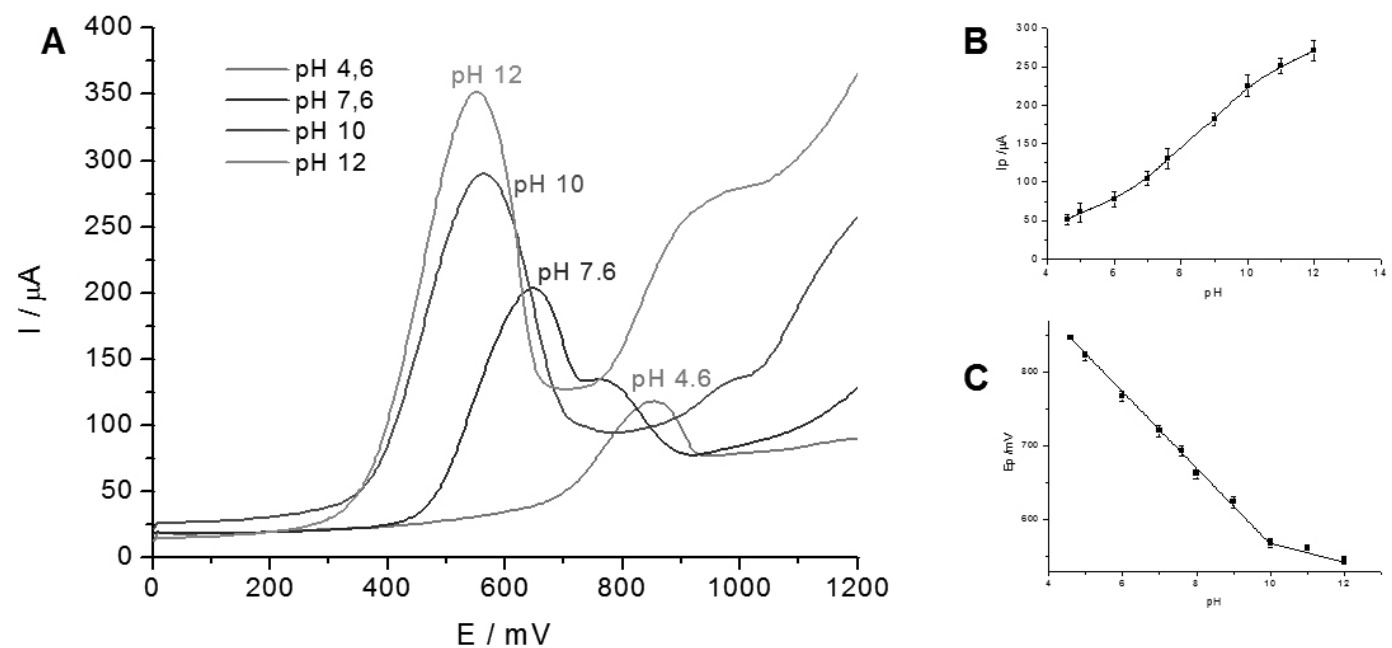

Figure 8. (A) Electrochemical behaviour of $1 \mathrm{mM} \mathrm{CP}$ at different $\mathrm{pH}$. (B) Ip $v s \mathrm{pH}$. (C) Ep vs pH. 

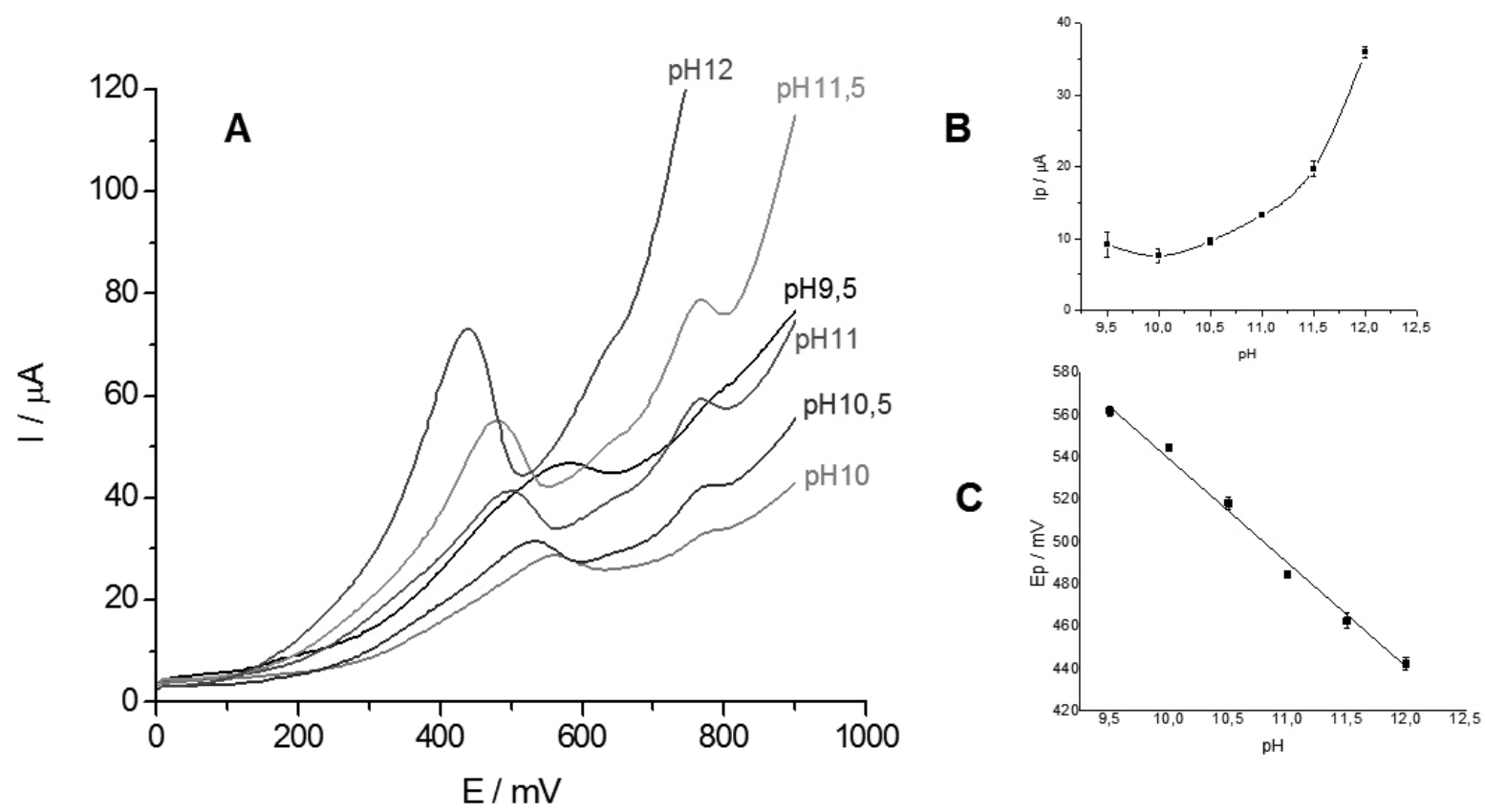

Figure 9. (A) Electrochemical behaviour of $1 \mathrm{mM}$ PE at different $\mathrm{pH}$. (B) Ip $v s \mathrm{pH}$. (C) Ep $v s \mathrm{pH}$

Selection of the experimental conditions for the determination of $P E$ and $C P$

To achieve the maximum sensitivity and the optimum conditions for the maximum adsorption, the influence of accumulation time on the peak current was evaluated (Fig. 10). The results showed that the oxidation peak current increased as the time, being the optimal of $180 \mathrm{~s}$ for PE and $240 \mathrm{~s}$ for CP.
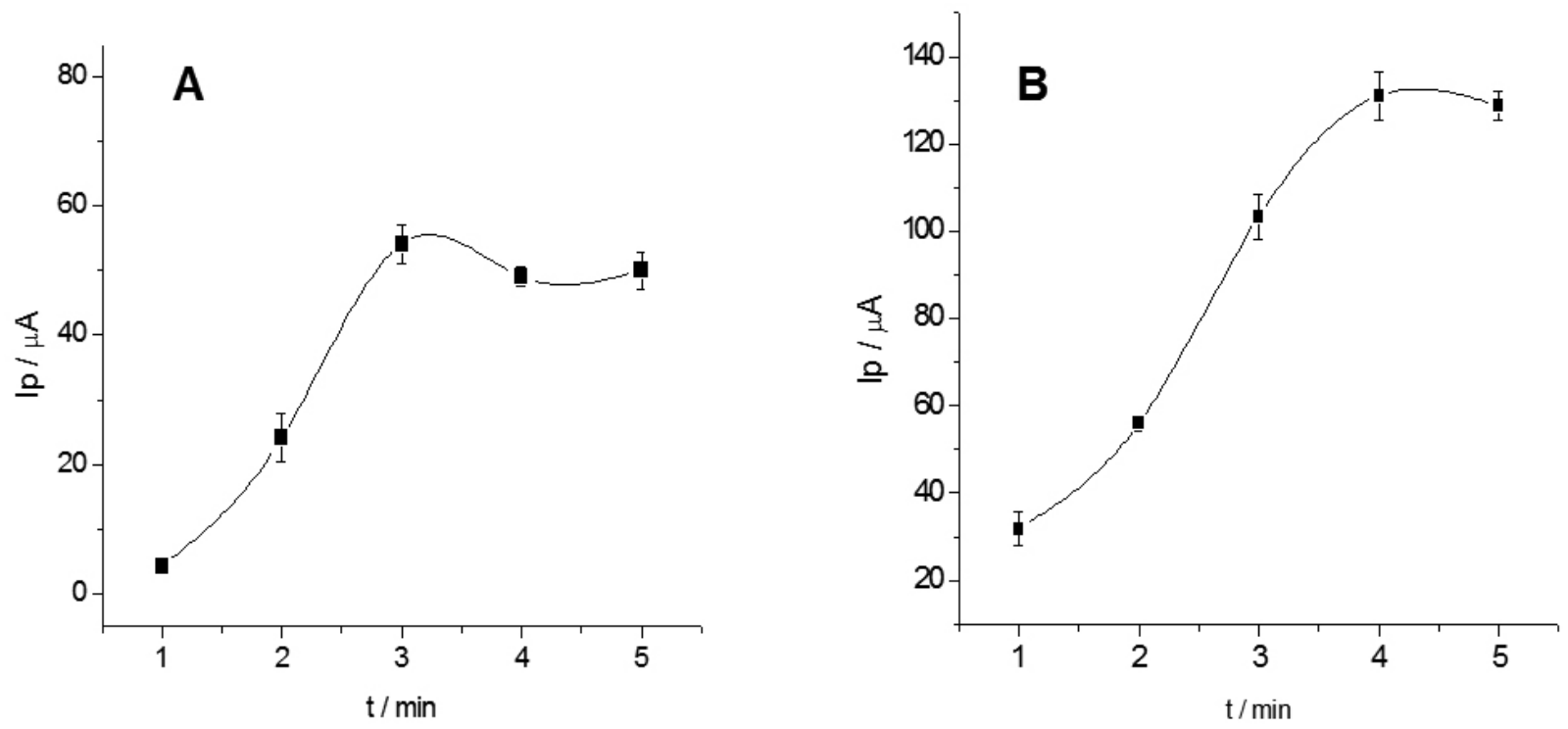

Figure 10. Peak current evolution over accumulation time (500 rpm) of (A) $0.1 \mathrm{mM} \mathrm{PE} \mathrm{(pH} \mathrm{12)} \mathrm{and} \mathrm{(B)} 0.1 \mathrm{mM} \mathrm{CP}(\mathrm{pH} 10)$.

Based on the results described above, an analytical method was proposed for determination of PE and CP individually and selectively in the same sample by using the developed modified electrode (MWCNTs-IL-gel/GCE).

A concentration study in $0.1 \mathrm{M}$ Britton-Robinson buffer was carried out with the optimal conditions selected for the determination of $\mathrm{CP}(\mathrm{pH} 10$, accumulation time of $240 \mathrm{~s}$ ) and $\mathrm{PE}(\mathrm{pH} \mathrm{12}$, accumulation time of $180 \mathrm{~s})$, and the analytical parameters were determined (Table 1).

The repeatability was examined by measuring the responses of 9 independent modified electrodes in a solution of $\mathrm{PE}\left(1 \times 10^{-3} \mathrm{M}, \mathrm{pH} 12\right)$ and $\mathrm{CP}\left(1 \times 10^{-3}\right.$ $\mathrm{M}, \mathrm{pH} 10)$. The coefficients of variation $(\mathrm{CV})$ in peak currents were found to be 4.5 and $3.2 \%$ for detecting $\mathrm{PE}$ and $\mathrm{CP}$, respectively.
Application

It can be observed in Fig. 11 that by using MWCNTs-IL-gel/GCE, it was possible to differentiate both signals; however this did not happen when it was measured with the electrode unmodified (bare GCE), where only one signal was observed (inset on Fig. 11A). This fact corroborates the advantage of using a modified electrode, since the selectivity of the electrode is improved. In addition, on Figure 11B, DPVs of standard solutions of PE and CP are compared with the mixture in the pharmaceutical sample solution, revealing that, when the modified electrode is used, there is no loss of sensitivity in the quantification of these drugs in the same sample. 
Table 1. Analytical parameters for the DPV method developed for PE and CP determination using a MWCNTs-IL-gel/GCE.

\begin{tabular}{|c|c|c|}
\hline Parameter & CP & $40.3-161.4$ \\
\hline Linear working range $(\mu \mathrm{g} / \mathrm{mL})$ & $0.39-27.4$ & $\mathrm{I}_{\mathrm{p}}=0.63 \times \mathrm{C}+23.6$ \\
\hline Linear regression $\left(\mathrm{I}_{\mathrm{p}}, \mu \mathrm{A} ; \mathrm{C}, \mu \mathrm{g} / \mathrm{mL}\right)$ & $\mathrm{I}_{\mathrm{p}}=3.07 \times \mathrm{C}+5.14$ & 0.999 \\
\hline$r^{2}$ & 3.2 & 4.5 \\
\hline Repeatability $(\mathrm{CV}, \%)$ & 4.3 & 32.4 \\
\hline Reproducibility $(\mathrm{CV}, \%)$ & 0.114 & 34.6 \\
\hline LOD $(\mu \mathrm{g} / \mathrm{mL})$ & 0.247 & $108.2 \pm 3.3$ \\
\hline LOQ $(\mu \mathrm{g} / \mathrm{mL})$ & $103.1 \pm 6.7$ & \\
\hline Recovery $(\%)$ & & \\
\hline
\end{tabular}
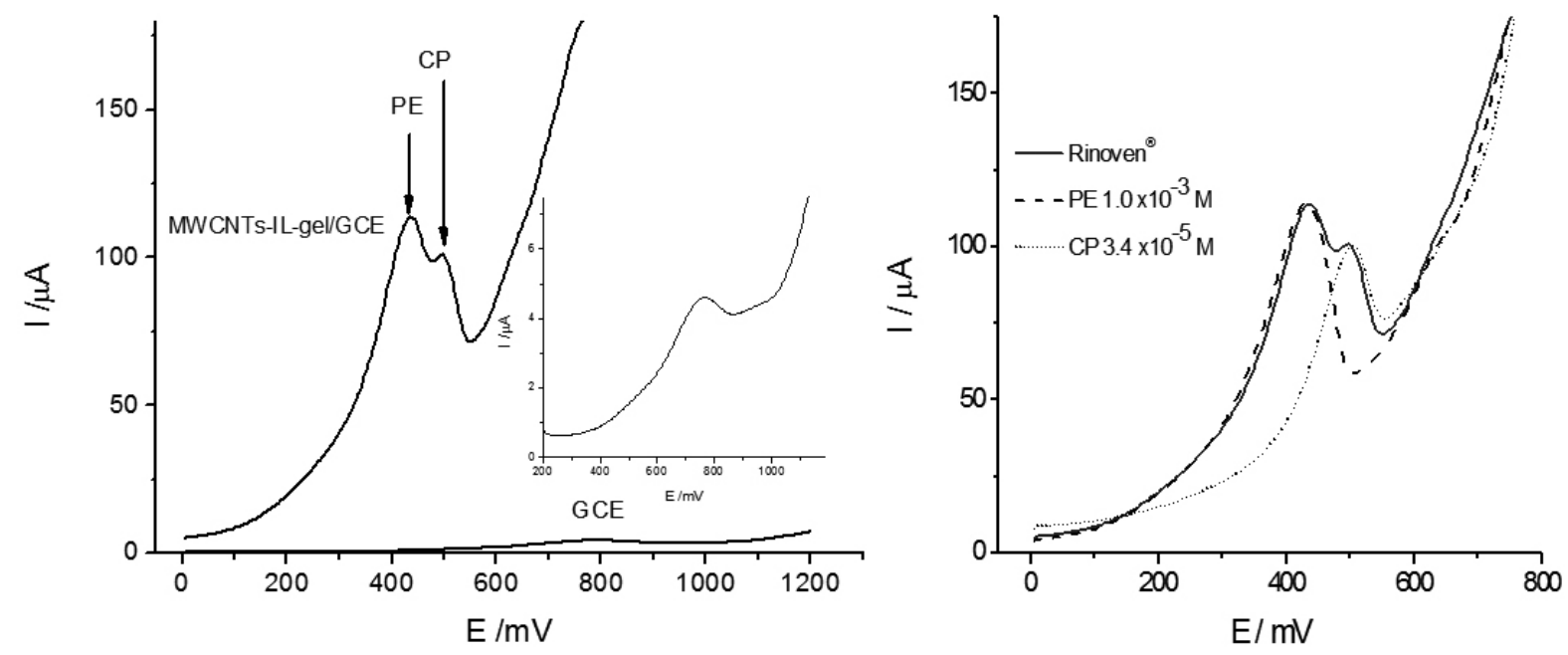

Figure 11. DPVs of (A) Rinoven ${ }^{\circledR}$ solution at GCE and MWCNTs-IL-gel/GCE, inset GCE. (B) Rinoven ${ }^{\circledR}$ solution (prepared at a concentration of $1 \times 10^{-3} \mathrm{M}$ for PE and $3.4 \times 10^{-5} \mathrm{M}$ for $\mathrm{CP}$ ) and standard solutions of $1 \times 10^{-3} \mathrm{M}$ PE and $3.4 \times 10^{-5} \mathrm{M} \mathrm{CP}(\mathrm{MWCNTs}-\mathrm{IL}-\mathrm{gel} / \mathrm{GCE}$ ).

Finally, the practical application of the proposed modified electrode was illustrated by simultaneously determining the concentrations of $\mathrm{PE}$ and $\mathrm{CP}$ in commercial pharmaceutical samples (Rinoven ${ }^{\circledR}$ tablets) by means of the standard addition method. The data obtained employing the herein proposed voltammetric procedure for tablet formulations were also compared to those obtained by the reverse-phase high-performance liquid chromatographic method (HPLC) with diode-array detection (DAD) ${ }^{10}$. The results of the assay for PE and $\mathrm{CP}$, were found to be $102.2 \% \pm 3.3 \%$ and $102.9 \% \pm 2.8 \%$ over declared amount for DPV, and $98.6 \% \pm 1.1 \%$ and $100.7 \% \pm 0.9 \%$ over declared amount for HPLC.

\section{CONCLUSIONS}

In the present study, a novel MWCNTs-IL-gel/GCE was fabricated and characterized to investigate the electrochemical oxidation behavior of $\mathrm{PE}$ and CP. The obtained results allow concluding that the MWCNTs-IL-gel/GCE could be promising alternative with a great potential for the quantitative and simultaneous determination of PE and CP in mixtures, as they are commonly found in pharmaceutical formulations.

\section{ACKNOWLEDGEMENTS}

The authors are grateful for the support of FONDECYT Grant No. 1150861 .

\section{REFERENCES}

1.- S.S. Hwang, J. Gorsline, J. Louie, D. Dye, D. Guinta, J. Clin. Pharmacol. 1995, 353, 259-267.

2.- S.U. Yasuda, A. Wellstein, P. Likhari, J.T. Barbey, R.L. Woosley, Clin.
Pharmacol. Ther. 1995, 58, 210-220

3.- X. Liu, L. Liu, H. Chen, X. Chen, J. Pharm. Biomed. Anal. 2007, 43 1700-1705.

4.- Y. Dong, X. Chen, Y. Chen, X. Chen, Z. Hu, J. Pharm. Biomed. Anal. 2005, 39, 285-289.

5.- C. Celma, J.A. Allué, J. Prunonosa, C. Peraire, R. Obach, J. Chromatogr A 2000, 870, 77-86.

6.- H.G Lou, H. Yuan, Z.R. Ruan, B. Jiang, J. Chromatogr. B 2010, 878, 682 688.

7.- H. Li, C. Zhang, J. Wang, Y. Jiang, J.P. Fawcett, J. Gu, J. Pharm. Biomed Anal. 2010, 51, 716-722.

8.- A. Acheampong, W.O. Gyasi, G. Darko, J. Apau, S. Addai-Arhin, Springerplus 2016, 5, 625 .

9.- E. Kalogria, M. Koupparis, I. Panderi, J. AOAC Int. 2010, 93, 1093-101.

10.- R.P. Viswanath, R.M. Useni, B. Varaprasad, P. Somasekhar, J. Pharm. Res. 2011, 4, 1225-1227.

11.- A. Yacobi, Z.M. Look, C.M. Lai, J. Pharm. Sci. 1978, 67, 1668-1670.

12.- M.D. Paciolla, S.A. Jansen, S.A. Martellucci, A.A. Osei, J. Pharm. Biomed. Anal. 2001, 26, 143-149.

13.- M. Gil-Agustí, L. Monferrer-Pons, M.C. García-Alvarez-Coque, J. Esteve -Romero, Talanta 2001, 54, 621-630.

14.- E. Jacobsen, K. Høgberg, Anal. Chim. Acta 1974, 71, 157-163.

15.- H.M. Abu-Shawish, Electroanalysis 2008, 20, 491-497.

16.- S.D. Lamani, R.N. Hegde, A.P. Savanur, S.T. Nandibewoor, Electroanalysis 2011, 23, 347-354.

17.- M. Amiri, M. Alimoradi, K. Nekoueian, A. Bezaatpour, Ind. Eng. Chem. Res. 2012, 51, 14384-14389.

18.- B. Muralidharan, G. Gopu, S. Laya, C. Vedhi, P. Manisankar, Mat. Sci. Appl. 2011, 2, 957-963.

19.- E.A. Khudaish, M. Al-Hinaai, S. Al-Harthy, K. Laxman, Electrochim. Acta 
2014, 135, 319-326.

20.- J.R. González Lomba, E. Pinilla Gil, P. Cintas Moreno, R.M. GarcíaMoncó Carra, A. Sánchez Misiego, J. Electroanal. Chem. 1996, 410, $87-$ 92.

21.- Y.-Q. Un, W. You, Z.-N. Gao, Chin. J. Appl. Chem. 2008, 01

22.- H. Ahmara, A. Reza Fakhari, Anal. Methods 2012, 4, 812-818.

23.- F. Anson, Anal. Chem. 1964, 36, 932-934.

24.- R. Adams, Electrochemistry at Solid Electrodes, Marcel Dekker, New York, 1969.

25.- T. Fukushima, A. Kosaka, Y. Ishimura, T. Yamamoto, T. Takigawa, N. Ishii, T. Aida, Science 2003, 300, 2072-2074.

26.- X. Liu, Z. Ding, Y. He, Z. Xue, X. Zhao, X. Lu, Colloids Surf. B
Biointerfaces. 2010, 79, 27-32.

27.- S. Bollo, N.F. Ferreyra, G.A. Rivas, Electroanalysis 2007, 19, 833-840.

28.- B. Pérez-Mella, A. Álvarez-Lueje, Electroanalysis 2013, 25, 2193-2199.

29.- C.O.Wilson, O Gisvold, JH. Block, JM. Beale, Wilson and Gisvold's textbook of organic medicinal and pharmaceutical chemistry. Philadelphia: Lippincott Williams \& Wilkins, 2004.

30.- A. Gaber, M. Mersal, J. Solid State Electrochem. 2012, 16, 2031-2039.

31.- A. Meareg, L. Worku, A. Shimelis, Anal. Bioanal. Chem. 2011, 4, 365 378.

32.- D.K. Gosser, Cyclic Voltammetry: Simulation and Analysis of Reaction Mechanisms, VCH, New York, 1993. 